\title{
The role of Wnt signaling pathway in atherosclerosis and its relationship with angiogenesis
}

\author{
JINGRU DU ${ }^{1}$ and JUNFENG $\mathrm{LI}^{2}$ \\ ${ }^{1}$ Department of Cardiology, The Second Affiliated Hospital of Fujian Medical University, Quanzhou, Fujian 362000; \\ ${ }^{2}$ Department of Orthopedics, The 180th Hospital of PLA (Affiliated Haixia Hospital of Huaqiao University), \\ Quanzhou, Fujian 362008, P.R. China
}

Received December 5, 2017; Accepted June 21, 2018

DOI: $10.3892 / \mathrm{etm} .2018 .6397$

\begin{abstract}
Expression and function of Wnt signaling pathway in rats with atherosclerosis (AS) were investegated. The AS model of rats was established after 8-week continuous feeding of a high-fat diet, with normal rats as the control. Blood was taken from the carotid artery to detect the level of blood lipid. Aortic slices were made to observe the pathological changes of the aorta after the rats were sacrificed. Enzyme-linked immunosorbent assay kits were used to detect the contents of interleukin-6 (IL-6) and tumor necrosis factor- $\alpha(\mathrm{TNF}-\alpha)$. Western blot analysis and semi-quantitative reverse transcription-polymerase chain reaction (RT-PCR) were performed to detect the expression levels of related proteins and mRNA in rat Wnt signaling pathway. Correlation analysis between the protein expression level of vascular endothelial growth factor (VEGF) and that of Wnt1 was conducted. Aortic slices showed that the ratio of intima thickness to media thickness of the rats in the model group was higher than that of in the control group $(\mathrm{P}<0.01)$. Blood lipid and the contents of IL- 6 and TNF- $\alpha$ of the rats in the model group were higher than those of the rats in the control group $(\mathrm{P}<0.01)$. Semi-quantitative RT-PCR indicated that mRNA expression levels of Wnt1, $\beta$-catenin and dickkopf1 in the aorta of rats in the model group were increased compared with those of control group $(\mathrm{P}<0.01)$. The results of western blot analysis revealed that the protein expression levels of Wnt1, $\beta$-catenin, DKK1 and VEGF of the rats in the model group were remarkably higher than those of the control group $(\mathrm{P}<0.01)$. The level of VEGF protein was positively correlated with that of Wnt1 $(\mathrm{P}<0.05$, $\mathrm{r}=0.7810$ ). The activation of Wnt signaling pathway in the aorta of the rats with AS can induce the expression of relevant inflammatory cytokines. It has the effects of promoting the progression of AS and accelerating angiogenesis.
\end{abstract}

Correspondence to: Dr Junfeng Li, Department of Orthopedics, The 180th Hospital of PLA (Affiliated Haixia Hospital of Huaqiao University), 180 Huayuan Road, Fengze, Quanzhou, Fujian 362008, P.R. China

E-mail: jra7b6@163.com

Key words: atherosclerosis, angiogenesis, Wnt signal pathways

\section{Introduction}

Atherosclerosis (AS) is frequently observed in middle-aged and aged people. It is a common cardiovascular disease, mainly manifested as increased blood lipid. The incidence of AS is increasing year by year with a high recurrence rate $(1,2)$. The pathogenesis of AS is complicated. It can be caused by a variety of reasons, mainly by lipid infiltration, increase of inflammatory response and endothelial cell injury (3). The treatment of AS is currently dominated by medication. The progression of the disease is inhibited through the reduction of the patient's blood lipid and the control of risk factors for the occurrence of AS; however, the treatment of AS faces great challenges. Patients need lifelong medication due to high recurrence rate and fatality rate of the disease. Therefore, it is urgent to illuminate the pathogenesis of AS and seek new treatment methods (4). A large number of studies have shown that the protein in the Wnt signaling pathway is highly expressed in a variety of cardiovascular diseases, and it has a certain relationship with multiple cardiovascular diseases $(5,6)$. Therefore, the study on the role of Wnt signal pathway in AS has been the direction of feasible studies of AS-targeted treatments.

Dickkopf1 (DKK1) protein is the target protein of Wnt/ $\beta$-catenin signaling pathway and plays an important role in the progression of multiple cardiovascular diseases. For example, myocardial infarction can affect the expression levels of various inflammatory factors and vascular endothelial growth factor (VEGF) in patients with myocardial infarction and influence angiogenesis, thus exerting impacts on the progression of cardiovascular diseases $(7,8)$. However, the role of Wnt signaling pathway in the progression of AS and its relationship with angiogenesis have not been studied yet. This study was conducted to investigate the role of Wnt signaling pathway via AS model of rats and explore the relationship between Wnt signaling pathway and angiogenesis in rats with AS.

\section{Materials and methods}

Animals and grouping. Twenty-four adult male Sprague-Dawley (SD) rats were purchased from the Animal Experimental Center (Guangdong, China). The experimental animals (production license no. SCXK2013-012; use license 
no. SYXK2014-008) weighed $250 \pm 10 \mathrm{~g}$. They were raised in a specific pathogen-free (SPF) animal room at a constant temperature $\left(25^{\circ} \mathrm{C}\right)$. They could eat and drink freely. High-fat fodder and sustaining fodder were purchased from the Animal Experimental Center. The aforementioned rats were divided into control group and model group with 12 rats in each group. The rats in the control group were fed with sustaining fodder, while those in the model group were fed with high-fat fodder. Eight weeks later, the level of blood lipid in the serum and the pathological changes in the aorta were detected to judge whether the model was successful. All the animals were operated strictly as per the regulations for experimental animals in the health guidance for the care and use of experimental animals specified by the National Institute. The study was approved by the Ethics Committee of The Second Affiliated Hospital of Fujian Medical University (Fujian, China).

Materials and instruments. TRIzol kits, reverse transcription kits, electrochemiluminescence (ECL) solution (all from Invitrogen; Thermo Fisher Scientific, Inc., Waltham, MA, USA), enzyme-linked immunosorbent assay-interleukin-6 (ELISA-IL-6) kits, ELISA-tumor necrosis factor- $\alpha$ (TNF- $\alpha$ ) kits (Wuhan Boster Biological Technology,Ltd.,Wuhan,China), rabbit anti-Wnt1, rabbit anti- $\beta$-catenin, rabbit anti-DKK1, rabbit anti-VEGF, rabbit anti-glyceraldehyde-3-phosphate dehydrogenase (GAPDH), horseradish peroxidase-labeled anti-rabbit secondary antibody (all from Cell Signaling Technology, Inc., Danvers, MA, USA), polymerase chain reaction (PCR) instrument, gel electrophoresis and transmembrane systems (both from Applied Biosystems; Thermo Fisher Scientific, Inc.), pipettors (Gilson, Inc., Middleton, WI, USA), ultraviolet imaging system (Biometra GmbH, Göttingen, Germany), fully automatic biochemical analyser (Toshiba, Tokyo, Japan) and electronic scales (BP121S; Sartorius AG, Göttingen, Germany). Other relevant instruments and reagents are illustrated in relevant sections. Rabbit polyclonal Wnt1 antibody (dilution 1/500; cat. no. ab15251); rabbit monoclonal $\beta$-catenin antibody (dilution 1/500; cat. no. ab32572); rabbit monoclonal DKK1 antibody (dilution 1/500; cat. no. ab109416); rabbit monoclonal VEGF antibody (dilution 1/500; cat. no. ab32152); rabbit polyclonal GAPDH antibody (dilution 1:500, cat. no. ab37168) and secondary goat anti-rabbit (HRP) IgG antibody (dilution 1/2,000; cat. no. ab6721) were all purchased from Abcam (Cambridge, MA, USA).

Detection of the level of blood lipid. After the rats in the model group were fed with high-fat diet and those in the control group were fed with common diet for 8 weeks, blood was taken from the carotid artery after 12-hour fasting. The blood was put into different centrifugal tubes, and they were allowed to stand for $30 \mathrm{~min}$. Then they were centrifuged for $10 \mathrm{~min}$ at $3,500 \mathrm{x} \mathrm{g}$. The supernatant was taken to obtain the serum and the plasma, respectively, which were stored at $-80^{\circ} \mathrm{C}$ for standby. The serum of the rats in each group was taken to detect the levels of total cholesterol (TC), low-density lipoprotein (LDL-C) and triglycerides (TG) using a fully automatic biochemical analyser.

Aortic slices and observation. The rats were sacrificed immediately after the blood was drawn. The chest was opened, and the blood vessels from the aortic valve to the bifurcation part of the abdominal aorta were cut and removed. The blood vessels were incised after the connective tissues and the fat outside the blood vessels were isolated completely under the microscope. Phosphate-buffered saline (PBS) was used to wash away the residual blood, and a freezing microtome was used to make aortic slices. The slices were treated under the following conditions, respectively: xylene, anhydrous ethanol, 95\% ethanol, 90\% ethanol, $80 \%$ ethanol and 70\% ethanol. They were washed with ultrapure water after the aforementioned treatments were completed. Then they were stained with hematoxylin for $10 \mathrm{~min}$ and washed with ultrapure water again. They were treated with $1 \%$ ammonia water, washed with ultrapure water, and stained with eosin for $2 \mathrm{~min}$. The slices were dehydrated, made transparent and sealed after they were washed with water. The pathological changes of aortic blood vessels of the rats in each group were observed under a microscope, and the ratio of intima thickness to media thickness of the aorta was calculated.

Detection of the level of inflammatory factors. The contents of IL-6 and TNF- $\alpha$ were detected using ELISA kits after the plasma of the rats in each group was obtained via centrifuging. The standard curves of IL- 6 and TNF- $\alpha$ were prepared respectively for the subsequent quantification tests. A total of $100 \mu \mathrm{l}$ plasma sample of each group diluted 10 times with sample diluent was added to the sample well. The plates were placed at the constant temperature $\left(37^{\circ} \mathrm{C}\right)$ for reaction for $60 \mathrm{~min}$ after they were sealed with plate-sealing membrane. The plates were patted to clear liquid inside, and corresponding biotin-labelled antibodies were added. Then the plates were sealed, and reacted for $60 \mathrm{~min}$ at $37^{\circ} \mathrm{C}$. The plates were washed with scrubbing solution 3 times ( $1 \mathrm{~min} / \mathrm{time}$ ) after the liquid in the plates were dried by patting. A total of $100 \mu \mathrm{l}$ affinity-peroxidase complex was added, and the plates were sealed and reacted for $30 \mathrm{~min}$ at $37^{\circ} \mathrm{C}$. The plates were washed with scrubbing solution 5 times ( $2 \mathrm{~min} / \mathrm{time}$ ) after the liquid in the plates were dried by patting. A total of $100 \mu$ reaction-terminating solution was added to stop reaction, and the optical density of each well at $450 \mathrm{~nm}$ were measured with a microplate reader (BioTek Instruments, Inc., Winooski, VT, USA). The levels of IL-6 and TNF- $\alpha$ in the plasma were calculated via standard curves.

Semi-quantitative reverse transcription-polymerase chain reaction $(R T-P C R)$. The samples taken from the carotid artery of the rats in each group were added to TRIzol kits at a ratio of $100 \mathrm{mg}: 1 \mathrm{ml}$. They were homogenated with an ultrasonic homogenizer until there was no visible debris. The supernate was taken after the samples were centrifuged at $4^{\circ} \mathrm{C}$ at $10,500 \mathrm{x}$ g. Ribonucleic acid (RNA) was extracted according to the instructions for RNA-extraction kits. The detection showed that the concentration and the purity of RNA were relatively good, and they could be used for the subsequent tests. RT-PCR was conducted to obtain complementary DNA (cDNA) using RT-PCR kits with RNA specimen as the template. Using this as a template, thermu aquaticus (Taq) PCR, Taq buffer solution, deoxy-ribonucleoside triphosphate (dNTP) mixture and distillation-distillation $\mathrm{H}_{2} \mathrm{O}\left(\mathrm{ddH}_{2} \mathrm{O}\right)$ were further added for PCR amplification on a PCR instrument. Finally, the product was placed on a quantitative PCR instrument to detect mRNA expression of the target gene. The reaction system volume was 
in total $25 \mu \mathrm{l}$, pre-denaturation at $95^{\circ} \mathrm{C}$ for $5 \mathrm{~min}$, denaturation at $95^{\circ} \mathrm{C}$ for $30 \mathrm{sec}$, annealing at $60^{\circ} \mathrm{C}$ for $45 \mathrm{sec}$, extension at $72^{\circ} \mathrm{C}$ for $3 \mathrm{~min}$, with 35 cycles, and then extension at $72^{\circ} \mathrm{C}$ for $5 \mathrm{~min}$. PCR products were stored at $4^{\circ} \mathrm{C}$. The sequences of Wnt1, $\beta$-catenin and DKK1 primers are indicated in Table I. The primers were synthesized by Tiangen Biotech Co., Ltd. (Beijing, China).

Western blot analysis. After the aortic tissues of the rats in each group were cut into pieces, they were added to radio immunoprecipitation assay (RIPA) lysis buffer at a ratio of $100 \mathrm{mg}: 1 \mathrm{ml}$. The resulting solutions were placed on an ice box, and homogenate processing was conducted using an ultrasonic homogenizer until there was no visible tissue. They were centrifuged at $10,500 \mathrm{x}$ g for $10 \mathrm{~min}$ at $4^{\circ} \mathrm{C}$. The supernatant (that is, total protein sample) was taken. The concentration of total protein in the aorta of the rats in each group was measured using BCA protein assay kits. Sample-loading buffer solution at the same concentration was prepared, and boiled for $15 \mathrm{~min}$ to inactivate the protein. The samples were added to the sample-loading wells after $10 \%$ separation gel and $4 \%$ concentration gel were prepared. Sodium dodecyl sulfate-polyacrylamide gel electrophoresis (SDS-PAGE) was conducted at $80 \mathrm{~V}$. Membrane transference was conducted at $100 \mathrm{~V}$ to transfer the protein to polyvinylidene fluoride (PVDF) membranes (IPVH00010; EMD Millipore, Billerica, MA, USA) after the electrophoresis was completed. Skim milk powder $(5 \%)$ was prepared, and sealed for $2 \mathrm{~h}$. After the target strip was cut, antibodies of Wnt1, $\beta$-catenin, DKK1, VEGF and GAPDH (dilution at 1:1,000) were prepared. The target strips were placed in corresponding antibodies, and incubated overnight at $4^{\circ} \mathrm{C}$. They were washed with Trisbuffered saline with Tween-20 (TBST) 3 times (10 min/time) after incubation. Horseradish peroxidase-labeled anti-rabbit secondary antibody (Cell Signaling Technology, Inc.) (dilution at 1:5,000) was prepared. The strips were washed with TBST 3 times ( $5 \mathrm{~min} /$ time) after they were incubated for $2 \mathrm{~h}$ at room temperature. ECL solution was prepared and dripped on each strip. The strips were placed in a dark box for pressing, and placed in developing solution and fixing solution for development. They were scanned after drying to analyze the gray value of each protein strip. Wnt1/GAPDH, $\beta$-catenin/GAPDH, DKK1/GADH and VEGF/GAPDH were used to compare the expression level of each protein.

Statistical analysis. The data of the study are expressed as means \pm standard deviation, and the data were analyzed by Statistical Product and Service Solutions (SPSS) 19.0 (IBM Corp., Armonk, NY, USA). t-test was conducted for the comparison between two groups. Pearson analysis was used to examine the correlation between VEGF and Wnt1 expression. $\mathrm{P}<0.05$ was considered to indicate a statistically significant difference.

\section{Results}

Detection of the level of blood lipid in the rats. The serum was obtained via isolation after the rat model was established. Fully automatic biochemical analyzer was used to detect the contents of TC, LDL-C and TG in the serum of the rats in
Table I. Sequences of qPCR primers.

Sequence

$\begin{array}{ll}\text { Wnt } & \text { F: 5'-TGGAATTGCAACACCCTGGA-3' } \\ & \text { R: 5'-TTGGGCGCTTCCCATCTTCTT-3' } \\ \beta \text {-catenin } & \text { F: 5'-GACACGCCACAGGACTACAAGAA-3' } \\ & \text { R: 5'-CGTATCCACCAGAGTGAAAAGAA-3' } \\ \text { DKK1 } & \text { F: 5'-ATGAGGCACGCTATGTGCTG-3' } \\ & \text { R: 5'-CTCGAGGTAAATGGCTGTGGTC-3' } \\ \text { GAPDH } & \text { F: 5'-GACATCAAGAAGGTGGTGAAGC-3' } \\ & \text { R: 5'-TGTCATTGAGAGCAATGCCAGC-3' }\end{array}$

F, forward; R, reverse; DKK1, dickkopf1.
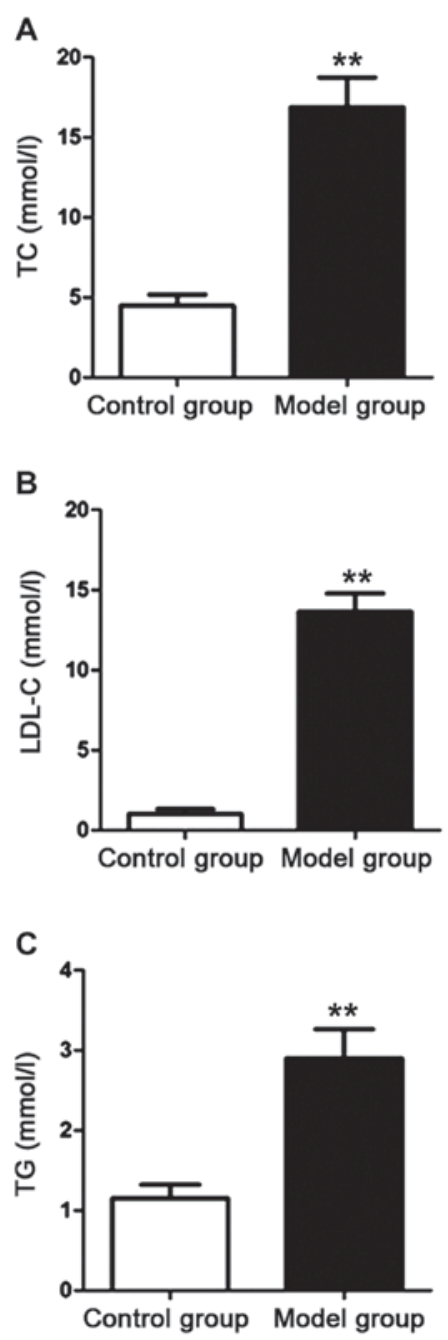

Figure 1. The contents of TC, LDL-C and TG in the serum of the rats in each group. (A) The content of TC. (B) The content of LDL-C. (C) The content of TG. The contents of TC, LDL-C and TG in the serum of the rats in the model group are significantly higher than those of the rats in the control group ("* $\mathrm{P}<0.01)$. TC, total cholesterol; LDL-C, low-density lipoprotein; TG, triglycerides.

the control group and the model group. The results are shown in Fig. 1. Compared with those of the rats in the control group, the contents of TC, LDL-C and TG of the rats in the model 


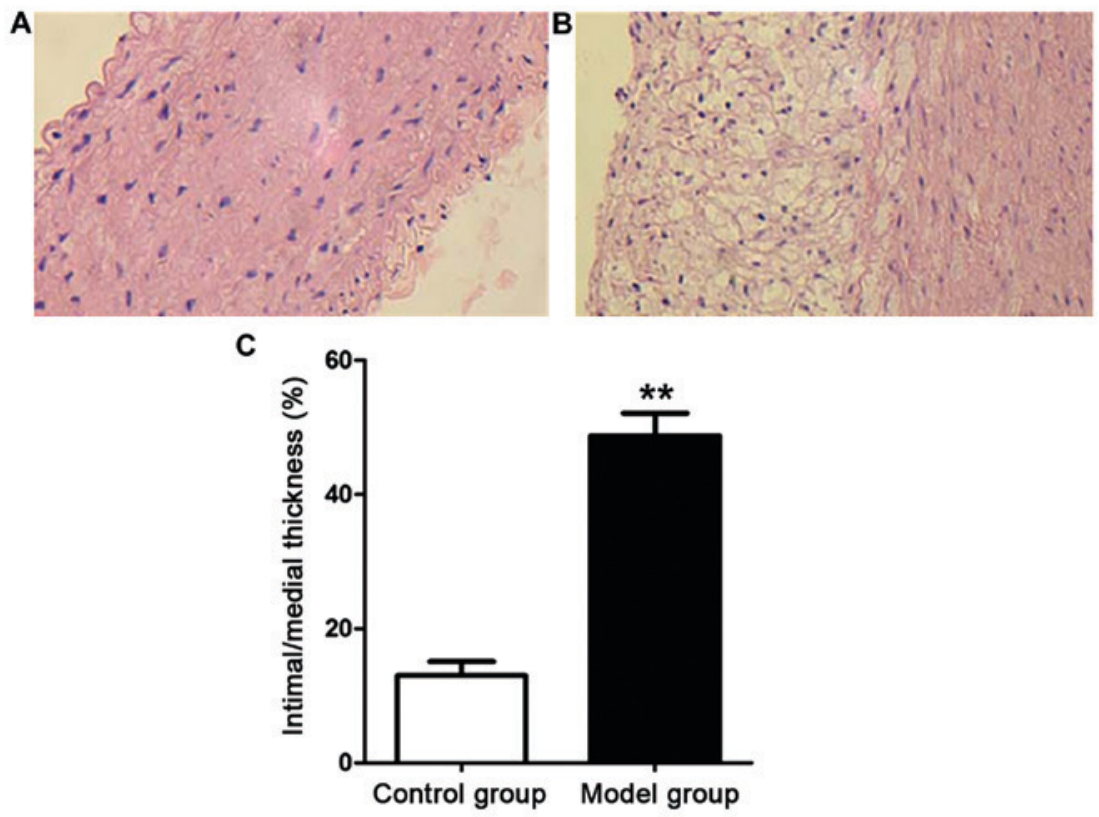

Figure 2. Observation of pathological changes and the thickening of media in the aorta of the rats under an optical microscope. (A) Micrograph of the aorta of the rats in the control group. (B) Micrograph of the aorta of the rats in the model group. (C) The ratio of intima thickness to media thickness of the rats. ${ }^{* *} \mathrm{P}<0.01$, compared with control group.

A

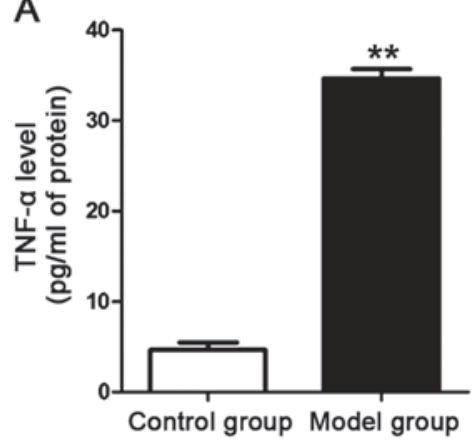

B

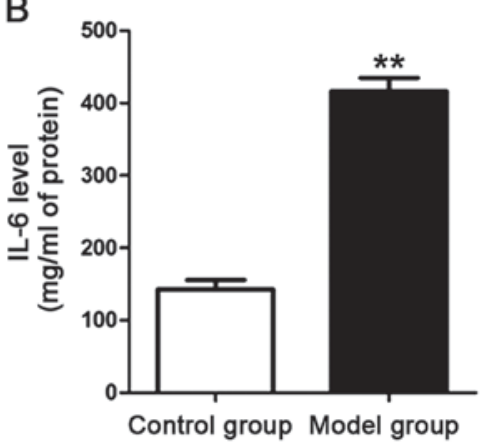

Figure 3. The contents of inflammatory factors in the rats. (A) The content of TNF- $\alpha$; (B) the content of IL- 6 . The contents of IL-6 and TNF- $\alpha$ in the plasma of the rats in the model group are notably higher than those of the rats in the control group $(* * \mathrm{P}<0.01)$. IL- 6 , interleukin- 6 ; TNF- $\alpha$, tumor necrosis factor- $\alpha$.

group were increased significantly. The differences were statistically significant $(\mathrm{P}<0.01)$.

Pathological changes in the aorta of the rats. Aortic slices of the rats in each group were prepared. The pathological changes in the aorta of the rats in each group were observed under an optical microscope (Fig. 2). The aortic intima of the rats in the control group was smooth on surface without the formation of lipid plaque by naked eye, while that of the rats in the model group was rough with significant thickening and the formation of lipid plaque. The ratio of intima thickness to media thickness of the rats in the model group was notably higher than that of the rats in the control group $(\mathrm{P}<0.01)$.

Detection of the contents of inflammatory factors in the plasma of the rats. The plasma was obtained via isolation after the rat model was established. ELISA kits for IL-6 and TNF- $\alpha$ were used to detect the contents of IL- 6 and TNF- $\alpha$ in the plasma of the rats in each group. The results are shown in Fig. 3. The contents of IL- 6 and TNF- $\alpha$ in the plasma of the rats in the model group were significantly higher than those of the rats in the control group. The differences were statistically significant $(\mathrm{P}<0.01)$.

Detection of $m R N A$ expression levels. The mRNA expression levels of Wnt1, $\beta$-catenin and DKK1 in the aorta of the rats in each group were detected with semi-quantitative RT-PCR after RNA in the aortic tissues of the rats in each group was extracted. The results are shown in Fig. 4. The mRNA expression levels of Wnt1, $\beta$-catenin and DKK1 in the aorta of the rats in the model group were significantly higher than those of the rats in the control group. The differences were statistically significant $(\mathrm{P}<0.01)$.

Detection of relative protein expression levels. The protein expression levels of Wnt, $\beta$-catenin, DKK1 and VEGF in the aorta of the rats in each group were detected with western 
A

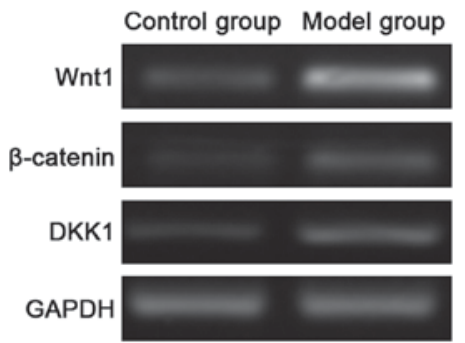

B

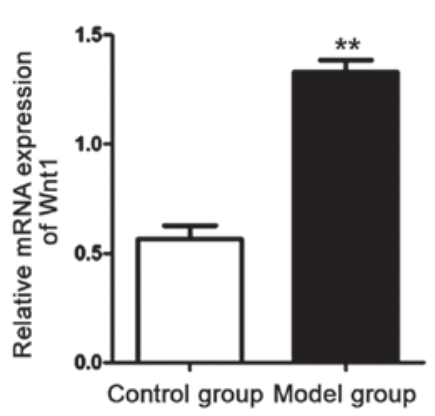

C

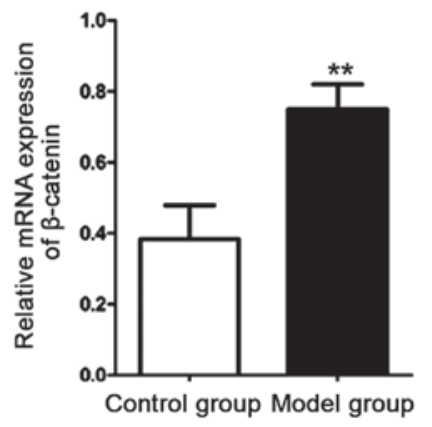

D

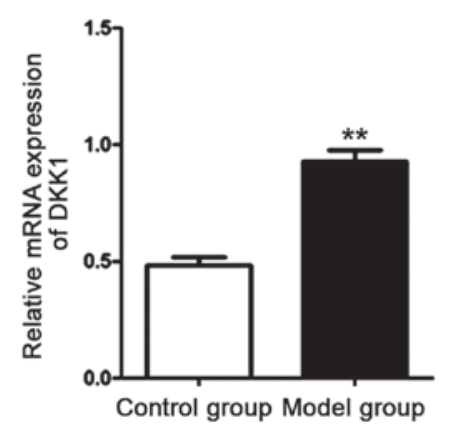

Figure 4. Detection of mRNA expression levels in the aorta of the rats in each group with semi-quantitative RT-PCR. (A) Strip figure of agarose gel. (B) Relative mRNA expression level of Wnt1. (C) Relative mRNA expression level of $\beta$-catenin. (D) Relative mRNA expression level of DKK1. The mRNA expression levels of Wnt1, $\beta$-catenin and DKK1 in the aorta of the rats in the model group are significantly higher than those of the rats in the control group $\left({ }^{* *} \mathrm{P}<0.01\right)$. DKK1, dickkopf1.

A

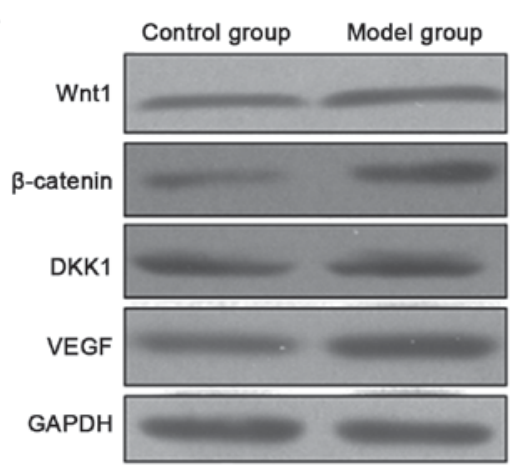

C

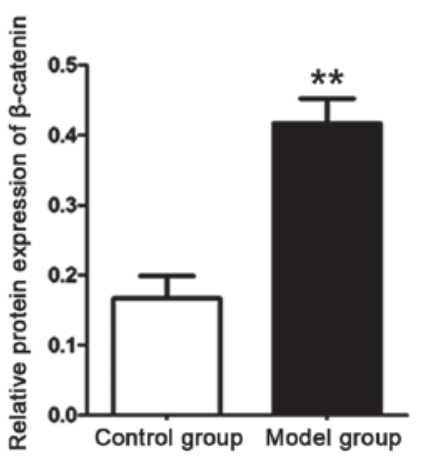

D

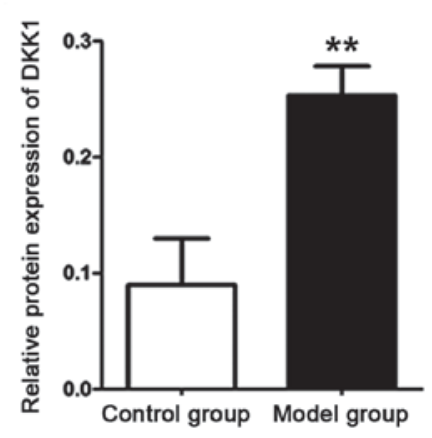

B

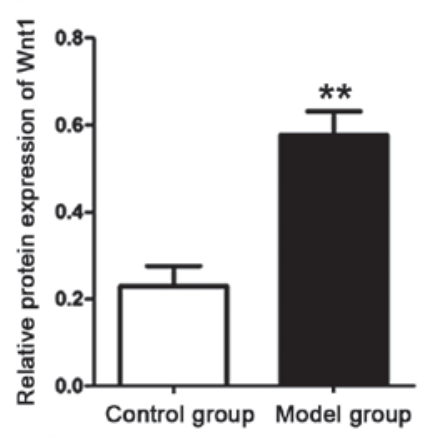

E

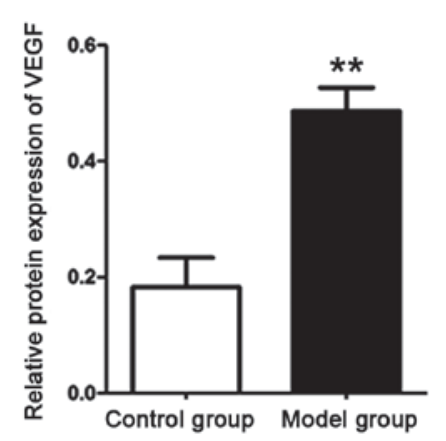

Figure 5. Detection of relevant protein expression levels in the aorta of the rats in each group with western blot analysis. (A) Strip figure. (B) Relative protein expression level of Wnt1. (C) Relative protein expression level of $\beta$-catenin. (D) Relative protein expression level of DKK1. (E) Relative protein expression level of VEGF. The protein expression levels of Wnt1, $\beta$-catenin, DKK1 and VEGF in the aorta of the rats in the model group are significantly higher than those of the rats in the control group $\left({ }^{* *} \mathrm{P}<0.01\right)$. DKK1, dickkopf1; VEGF, vascular endothelial growth factor.

blot analysis after total protein in the aortic tissues of the rats in each group was extracted. The results are shown in Fig. 5. The protein expression levels of Wnt1, $\beta$-catenin, DKK1 and
VEGF in the aorta of the rats in the model group were significantly higher than those of the rats in the control group. The differences were statistically significant $(\mathrm{P}<0.01)$. 


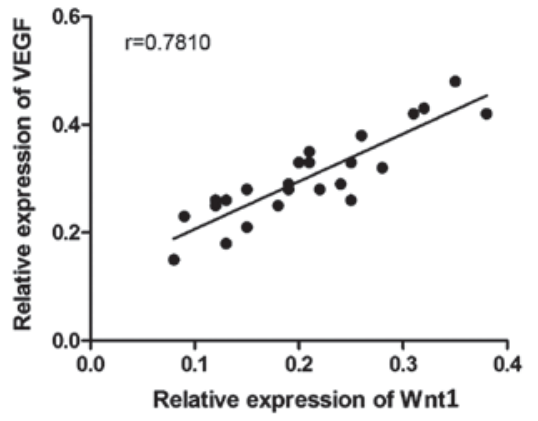

Figure 6. The correlation analysis between the relative protein expression level of Wnt1 and that of VEGF in the aorta of the rats. The protein expression level of Wnt1 in the aorta of the rats is positively correlated with that of VEGF $(\mathrm{P}<0.01, \mathrm{r}=0.7810)$. VEGF, vascular endothelial growth factor.

Correlation analysis. The correlation analysis between the expression level of Wntl and that of VEGF of the rats in the control group and the model group was conducted. The result is shown in Fig. 6. The protein expression level of Wnt1 in the aorta of the rats was positively correlated with that of VEGF $(\mathrm{P}<0.01, \mathrm{r}=0.7810)$.

\section{Discussion}

Atherosclerosis is the pathogenetic basis of a variety of cardiovascular diseases. It shows a dynamic evolution. Vascular wall injury is caused by the precipitation of the lipid in the vascular wall. The cells of the vascular smooth muscle continue to proliferate under the combined action of various reasons and continue to transfer to the site where the vascular medial plaque is formed, thus aggravating the formation of AS $(9,10)$. Vascular intimal injury caused by AS will result in the release of various inflammatory factors, which provides necessary environmental factors for the continuous development and deterioration of AS $(11,12)$. The formation of AS will lead to ischemia or necrosis of the tissues whose blood and oxygen are supplied by this part, and the body will establish collateral circulation in case of ischemia or necrosis of the tissues to resist poor environments. Some of the blood vessels show compensated regeneration (13). The process is called angiogenesis which occurs in various cardiovascular diseases $(14,15)$. Recently, a large number of studies found that Wnt signaling pathway is involved in the proliferation and apoptosis process of a variety of cells, affecting the occurrence and development of multiple physiological processes. Studies have shown that the protein expression levels of $\beta$-catenin and DKK1 are significantly increased during the formation of vascular endothelial cells, which indicated that Wnt signaling pathway participates in regulating the formation of vascular endothelial cells (16). A study (17) showed that the endothelial injury will activate Wnt signaling pathway, resulting in increased expression of $\beta$-catenin protein, further aggravating the infiltration of inflammatory factors, and promoting the formation of vascular plaque.

AS model of rats was established in this study; the detection showed that the contents of TC, TG and LDL-C in the serum of the rats in AS model were increased significantly, the vascular wall of the rats in the model group was thickened obviously, and that the ratio of intima thickness to media thickness was increased significantly. The aforementioned results indicated that the AS model of rats was established successfully in this study. It was previously (18) shown that the reduction of LDL-C can effectively prevent the occurrence of multiple cardiovascular diseases. The regulation of the lipid level in the serum is an important means for the prevention and treatment of AS clinically. The occurrence of AS is accompanied with the release of various inflammatory factors. IL- 6 and TNF- $\alpha$, as common pro-inflammatory factors, are generated by the activation of $\mathrm{T}$ cells and fibroblasts. This study revealed that the contents of IL- 6 and TNF- $\alpha$ in the plasma of the rats in the model group were significantly increased. The release of inflammatory factors induced by AS provided important environmental basis for the activation of Wnt signaling pathway. This study also showed that mRNA expression levels of Wnt signaling pathway-related proteins in the aortic blood vessels of the rats in AS model group were increased remarkably, and the expression levels of corresponding proteins were also higher than those of normal rats. The above results indicated that the activation of Wnt signaling pathway in AS model is involved in the regulation of AS progression. The activation of Wnt signaling pathway will result in the generation of a large amount of free $\beta$-catenin, cause dysfunction of vascular endothelium, and destroy the barrier function of vascular endothelium, thus further aggravating the development of AS (19). As an important protein of angiogenesis, VEGF plays an irreplaceable role in labeling angiogenesis (20). This study suggested that the expression level of VEGF of the rats in AS model group was increased significantly, which was positively correlated with the expression level of Wnt1. The above results suggested that Wnt signaling pathway also has the effect of regulating angiogenesis, but how it regulates the expression of angiogenic proteins and how it influences angiogenesis were not researched deeply in this study.

In conclusion, AS can result in increased level of blood lipid, promote the release of inflammatory factors, and activate Wnt signaling pathway in the aorta. The activation of Wnt signaling pathway can also aggravate the progression of AS and promote angiogenesis, but the specific molecular mechanism needs to be studied further.

\section{Acknowledgements}

Not applicable.

\section{Funding}

No funding was received.

\section{Availability of data and materials}

The datasets used and/or analyzed during the present study are available from the corresponding author on reasonable request.

\section{Authors' contributions}

JL conceived and designed the study, and drafted the manuscript. JD collected, analyzed and interpreted the experimental data, and revised the manuscript critically for important intellectual content. Both authors read and approved the final study. 


\section{Ethics approval and consent to participate}

The study was approved by the Animal Ethics Committee of Fujian Medical University Animal Center (Fujian, China).

\section{Patient consent for publication}

Not applicable.

\section{Competing interests}

The authors declare that they have no competing interests.

\section{References}

1. Dolan H, Crain B, Troncoso J, Resnick SM, Zonderman AB and Obrien RJ: Atherosclerosis, dementia, and Alzheimer disease in the Baltimore Longitudinal Study of Aging cohort. Ann Neurol 68: 231-240, 2010

2. Yamamoto S, Zhong J, Yancey PG, Zuo Y, Linton MF, Fazio S, Yang H, Narita I and Kon V: Atherosclerosis following renal injury is ameliorated by pioglitazone and losartan via macrophage phenotype. Atherosclerosis 242: 56-64, 2015.

3. Rose H, Low H, Dewar E, Bukrinsky M, Hoy J, Dart A and Sviridov D: The effect of HIV infection on atherosclerosis and lipoprotein metabolism: A one year prospective study. Atherosclerosis 229: 206-211, 2013.

4. Alberts-Grill N, Denning TL, Rezvan A and Jo H: The role of the vascular dendritic cell network in atherosclerosis. Am J Physiol Cell Physiol 305: C1-C21, 2013.

5. Bauer AJ and Martin KA: Coordinating regulation of gene expression in cardiovascular disease: Interactions between chromatin modifiers and transcription factors. Front Cardiovase Med 4: 19, 2017.

6. Gajjala PR, Sanati M and Jankowski J: Cellular and molecular mechanisms of chronic kidney disease with diabetes mellitus and cardiovascular diseases as its comorbidities. Front Immunol 6: 340, 2015.

7. Garcia-Martín A, Reyes-Garcia R, García-Fontana B, Morales-Santana S, Coto-Montes A, Muñoz-Garach M, Rozas-Moreno P and Muñoz-Torres M: Relationship of Dickkopf 1 (DKK1) with cardiovascular disease and bone metabolism in Caucasian type 2 diabetes mellitus. PLoS One 9: e111703, 2014.
8. Register TC, Hruska KA, Divers J, Bowden DW, Palmer ND, Carr JJ, Wagenknecht LE, Hightower RC, Xu J, Smith SC, et al: Plasma Dickkopf1 (DKK1) concentrations negatively associate with atherosclerotic calcified plaque in African-Americans with type 2 diabetes. J Clin Endocrinol Metab 98: E60-E65, 2013.

9. Witztum JL and Lichtman AH: The influence of innate and adaptive immune responses on atherosclerosis. Annu Rev Pathol 9: 73-102, 2014.

10. Geng YJ and Jonasson L: Linking immunity to atherosclerosis: Implications for vascular pharmacology - a tribute to Göran K. Hansson. Vascul Pharmacol 56: 29-33, 2012.

11. Taghavie-Moghadam PL, Butcher MJ and Galkina EV: The dynamic lives of macrophage and dendritic cell subsets in atherosclerosis. Ann N Y Acad Sci 1319: 19-37, 2014.

12. Patel KM, Strong A, Tohyama J, Jin X, Morales CR, Billheimer J, Millar J, Kruth H and Rader DJ: Macrophage sortilin promotes LDL uptake, foam cell formation, and atherosclerosis. Circ Res 116: 789-796, 2015.

13. Fontes JA, Rose NR and Čiháková D: The varying faces of IL-6: From cardiac protection to cardiac failure. Cytokine 74: 62-68, 2015.

14. Orbay H, Hong H, Zhang Y and Cai W: PET/SPECT imaging of hindlimb ischemia: Focusing on angiogenesis and blood flow. Angiogenesis 16: 279-287, 2013.

15. Bogdanovich S, Kim Y, Mizutani T, Yasuma R, Tudisco L, Cicatiello V, Bastos-Carvalho A, Kerur N, Hirano Y, Baffi JZ, et al: Human IgG1 antibodies suppress angiogenesis in a target-independent manner. Signal Transduct Target Ther 1: 458-463, 2016

16. Xu Y, Chen B, George SK and Liu B: Downregulation of MicroRNA-152 contributes to high expression of DKK1 in multiple myeloma. RNA Biol 12: 1314-1322, 2015.

17. Mozos I and Marginean O: Links between vitamin D deficiency and cardiovascular diseases. BioMed Res Int 2015: 109275, 2015.

18. Taghavie-Moghadam PL, Gjurich BN, Jabeen R, Krishnamurthy P, Kaplan MH, Dobrian AD, Nadler JL and Galkina EV: STAT4 deficiency reduces the development of atherosclerosis in mice. Atherosclerosis 243: 169-178, 2015.

19. Caliceti C, Nigro P, Rizzo P and Ferrari R: ROS, Notch, and Wnt signaling pathways: Crosstalk between three major regulators of cardiovascular biology. BioMed Res Int 2014: 318714, 2014.

20. Zhou H, Binmadi NO, Yang YH, Proia P and Basile JR: Semaphorin 4D cooperates with VEGF to promote angiogenesis and tumor progression. Angiogenesis 15: 391-407, 2012.

(i) $\Theta$ This work is licensed under a Creative Common EY NC ND Attribution-NonCommercial-NoDerivatives 4.0 International (CC BY-NC-ND 4.0) License. 